\title{
TRANSTERRITORIALIDAD E IDENTIDAD EN LA LITERATURA NORTEAFRICANA DE EXPRESIÓN EN CASTELLANO
}

\section{Transterritoriality and identity in the North African literature written in Spanish}

\author{
M'BARE N'GOM FAYE \\ Morgan State University \\ mbare.ngom@morgan.edu
}

Recibido: enero 2019 Aceptado: junio 2019

Cómo citar: N'gom Faye, M. (2019). Transterritorialidad e identidad en la literatura norteafricana de expresión en castellano. Revista De Estudios Africanos, páginas 51-81 doi: http://doi.org/10.15366/reauam2019.0.003

\section{Resumen}

Este ensayo se propone estudiar la representación de la identidad en la literatura norteafricana de expresión en español o literatura "Magrebí" de expresión en español. Asimismo, se centrará en la producción cultural así como en la historiografía literaria de los creadores culturales norteafricanos o magrebíes que escriben en español. A tal efecto, el trabajo se apoyará, en parte, en la producción cultural de autores y autoras como Sukina Aali-Taleb, Liman Boicha, Zahra El Hasnaui, de la República Árabe Saharaui Democrática (RASD), Abderrahman El Fathi, Ahmed Daoudi, y Mohammed Lahchiri (Marruecos) y Ridha Mami, (Túnez), entre otros.

Palabras clave: Literatura; magrebi; hispanomagrebí; República Árabe Saharaui Democrática; norteafricano.

\section{Abstract}

This essay intends to study the representation of identity in North African literature in Spanish or Maghrebian literature in Spanish with focus on both the cultural production and the literary historiography of North African or Maghrebian writers in Spanish. The study will analyze works by authors such as Sukina Aali-Taleb, Liman Boicha, Zahra El Hasnaui from the Sahrawi Arab Democratic Republic (SADR), Abderrahman El Fathi, Ahmed Daoudi, y Mohammed Lahchiri (Morocco) y Ridha Mami, (Tunisia), among others.

Key Words: Literature; Maghrebian; Hispanic Maghrebian; Sahrawi Arab Democratic Republic; North African. 
En este ensayo nos proponemos examinar y analizar las distintas estrategias discursivas de representación de la identidad en la literatura norteafricana de expresión en español o literatura "Magrebí" de expresión en español. Asimismo, el trabajo se centrará en la producción cultural así como en la historiografía literaria de los agentes culturales norteafricanos o magrebíes que escriben en lengua castellana, una expresión cultural y estética que ha recibido limitada atención crítica y teórica de parte de los estudiosos tanto en África como en Europa o en las Américas. A tal efecto, nos apoyaremos, en parte, en la producción cultural de autores y autoras saharauis, marroquíes y tunecinos, entre otros.

La literatura norteafricana de expresión en español también denominada "literatura hispanomagrebí"(Gahete et al. 2008), literatura magrebí de expresión española (Benumeya Grimau, 2008) o "literatura española escrita en el Magreb" (Gahete et al. 2008) en general, empezó a recibir cierta atención académica de parte de algunos estudiosos españoles y marroquíes en la última década del siglo XX. Para los fines de este estudio, proponemos el concepto descriptivo de "literatura norteafricana de expresión en castellano" o literatura magrebi de expresión en castellano". ${ }^{1}$ Ambas expresiones son intercambiables en tanto y en cuanto nos permite definir y delimitar mejor los parámetros teóricos y críticos pertinentes dentro del marco de la literatura africana de expresión en español o literatura africana hispana. Por lo tanto, el marco geográfico es África del Norte, y más específicamente el espacio designado como el Magreb,

Le terme Maghreb (en arabe, al-Djazirat al-Maghrib, «la presqu'île du couchant») a longtemps désigné les trois pays d'Afrique du Nord-Ouest: le Maroc, l'Algérie et la Tunisie. Puis, s'ajoutèrent les extrémités orientale et occidentale que sont la Libye et la Mauritanie. À ces cinq États regroupés depuis 1989 au sein de l'Union du Maghreb arabe(UMA) s'intègre également le territoire contesté du Sahara occidental, situé entre la Mauritanie et le Maroc, et occupé par ce dernier à $80 \%$ depuis 1979 . Les six pays ont une superficie totale de plus de six millions de $\mathrm{km}^{2}$ et forment, depuis plus d'un millénaire, une unité géographique, linguistique et religieuse. $^{2}$

\footnotetext{
${ }^{1}$ Véase Manuel Gahete, Abdellatif Limami, Ahmed M. Mgara, José Sarria y Aziz Tazi (2008) "Estudio introductorio", en Calle del Agua, pp. 29-42.

${ }^{2}$ http://www.axl.cefan.ulaval.ca/afrique/maghreb.htm. Consultado el 21 de diciembre de 2018. Para Manuel Gahete et al. (2008), "La localización geográfica del Magreb coincide con la parte más occidental del Mundo Árabe (el Poniente). En todas las referencias tradicionales se ha visto identificando al Magreb con la zona noroeste de África, que
} 
Tanto en Marruecos, Túnez como Argelia, la literatura escrita en lengua castellana es una expresión cultural y estética que comparte el mismo espacio de producción y, marginalmente, de consumo, en un sentido general, con otras expresiones culturales y estéticas nacionales, contemporáneas y dinámicas como la literatura magrebí en árabe normativo o moderno, la literatura magrebí en lengua francesa y las expresiones culturales y estéticas en lenguas vernáculas como el Dariya o el Amazighe en Marruecos, el Chilh y lenguas bereberes como chaouia y el nafussi en Túnez, y el Hassaniya en el Sáhara Occidental cuyas circunstancias políticas particulares hacen que el lugar de enunciación y/o espacio de producción no coincide necesariamente con el espacio de consumo. Si bien existe una bibliografía bastante amplia sobre el Sáhara Occidental desde la historia y otras disciplinas en las ciencias sociales, poca atención crítica y teórica ha sido dedicada a la literatura del Sáhara Occidental escrita en lengua castellana.

Hacia finales de los años 90 del siglo XX, la literatura africana en español empieza a despertar el interés de la prensa en España. En su entrega del 16 de abril de 2000, el periódico El País, uno de los periódicos españoles de mayor difusión e influencia en la Península, publicó un artículo titulado, "Las editoriales españolas descubren a los autores africanos que escriben en español". ${ }^{3}$ Si bien el enfoque inicial del artículo era la literatura de Guinea Ecuatorial, sacó a la luz la existencia de autores y autoras africanos y africanas que escriben en lengua castellana. Juana Vera, la autora del artículo, observa, "España empieza a publicar a autores africanos que escriben en lengua castellana". ${ }^{3}$ El ensayo de Juana Vera marco un hito muy importante dentro de la historiografía literaria africana hispana porque por primera vez, esta producción cultural llegó a los espacios públicos de transacción y de interacción no académicos de la Península Ibérica. Hasta entonces, las referencias a la literatura africana de expresión en castellano estaban mayormente limitadas a la literatura de Guinea Ecuatorial. Asimismo, Vera recalca, “(..) sus orígenes abarcan Guinea Ecuatorial, ex colonia española, Marruecos, Camerún, la República Democrática del Congo o Costa de Marfil" (Vera, 1). ${ }^{4}$ Con ello, la articulista amplia el campo de producción y de expresión, y por el otro

incluye los países de Marruecos, Túnez y Argelia” (p. 21).

${ }^{3}$ Ibidem.

${ }^{4}$ No queda claro si la omisión de los autores y autoras saharauis es intencional. 
lado, sorprendentemente, Juana Vera no hace ninguna referencia a la literatura saharaui escrita en castellano o, mejor dicho, no menciona a ningún autor o autora del Sáhara occidental. Un año más tarde, en enero de 2001, la revista Mundo Negro, órgano de los Misioneros Cambonianos, publico una sección especial titulada "La literatura hispanoafricana: puesta de largo" con motivo de la celebración de dos grandes encuentros culturales internacionales sobre la literatura africana de expresión en español que tuvieron lugar en España: Primer Encuentro de escritores africanos en lengua española organizado por el Centro de Estudios Africanos de la Universidad de Murcia en la ciudad de Murcia entonces dirigido por el escritor guineoecuatoriano Donato Ndongo-Bidyogo Makina, y Las Primeras Jornadas de Literatura hispanoafricana auspiciadas por el Colegio Mayor Nuestra Señora de África en Madrid. ${ }^{5}$ Mundo Negro titula el evento como un "gran acontecimiento cultural" porque era el primer congreso de su género que se celebraba en España. Ese renovado interés por la literatura africana en general, y la literatura africana en lengua castellana, en particular, sería corroborado por el periodista José María Ridao en un artículo publicado en la sección del cultural del periódico El País en su edición del 10 de marzo del 2001. José María Ridao, se refirió a la literatura de Guinea Ecuatorial como "única literatura africana que se expresa en nuestra lengua". Un rápido vistazo a la historiografia literaria africana hispana de finales del siglo XX revela la emergencia de "nuevos" agentes culturales en lengua castellana en el campo de la literatura africana hispana.

La literatura norteafricana de expresión en castellano no es un fenómeno cultural y estético reciente, está estrechamente vinculada a la situación política y geoestratégica de la Península Ibérica con respecto al continente africano, así como a los lazos históricos, económicos y culturales que han existido entre la península y el norte de África y el Magreb, en general. Por su proximidad geográfica, el continente africano ha estado presente en el imaginario público y político de los reinos de la Península Ibérica mucho antes del siglo VIII. Tomás García Figueras (1945) escribe al respecto:

Pocas precisiones necesita la situación de España en relación con la Europa occidental y con el continente africano; España funde la solución de continuidad de los dos continentes que, tangentes en el Estrecho de Gibraltar, se unen a través del

${ }^{5} \mathrm{El}$ congreso se celebró en Murcia del 27 al 29 de noviembre y del 1 al 2 de diciembre en Madrid. 
puente que es España. España, se ha dicho en todos los tonos y en todas las ocasiones, no es Europa ni es África, es un país de transición entre los dos continentes, con una misión, en consecuencia, perfectamente definida en la puesta en valor del continente africano (pp. 32-33)

Durante el reinado de los Reyes Católicos, la visión geopolítica de los monarcas españoles estaba guiada por lo que se conocía como el "ideal africanista de la Reina Católica" o "empresa africana de la Reina Católica”, una visión de estado que se podía resumir como una, "verdadera cruzada contra el turco y contra el Islam". ${ }^{6}$ Esa temprana "política exterior" norteafricana estaba definida por la defensa de la fe católica y formaba parte de la estrategia de contención del avance del Islam al tiempo que se proyectaba la influencia del cristianismo en la tierra de los "infieles". El objetivo último de ese "africanismo" de la primera hora era "la ocupación del Norte de Africa; [la] cristianización; [la] lucha contra el turco y recuperar para el Cristianismo los Santos Lugares". ${ }^{7}$ La "acción africana de España" no se consolidaría hasta la segunda mitad del siglo XIX con la ocupación del asentamiento de Villa Cisneros en el Sáhara Español en 1884. Lo que Joaquín Costa, uno de los hombres políticos más prominentes de la España decimonónica finesecular, llamó "la cuestión africana", se enmarca dentro del naciente proyecto africanista español del siglo XIX. Sin embargo, era una visión de estado que se limitaba sobre todo al Norte de África, y más específicamente al norte de Marruecos y al territorio de Ifni. Mariano de Castro y María Luisa de la Calle (1992) observan en este sentido que,

(...) la mayoría de la gente entendía que se trataba de la cuestión de Marruecos, expresaba una realidad que se ha mantenido durante mucho tiempo: el africanismo español se ha volcado en su casi totalidad sobre el mundo magrebí. (p. 7)

Esa percepción y representación pública y política de África esta profusamente recogida en la historiografía literaria, ensayística así como otras expresiones culturales y estéticas e institucionales españolas del siglo XV en adelante. Las representaciones de África del Norte a través de lo que Carlos Rodríguez Joulia denomina "África a través de la literatura Española”, están conformadas por un corpus de escritos heteróclitos y

${ }^{6}$ Véase Tomás García Figueras (1966) "La acción africana de España entorno al 98" Madrid, CSIC/IEA, p. 27.

${ }^{7}$ Ibidem, p. 22. 
heterogéneos que incluía a autores tan dispares como Diego de Hurtado Mendoza, Martín de Herrera, Jerónimo Contreras, Miguel de Cervantes, Lope de Vega, Calderón de la Barca, Ruiz de Alarcón, y que se apoyaba en una diversidad de plataformas discursivas entre las cuales destacaban las crónicas literarias e históricas, las relatos cortos, las obras dramáticas, los ensayos, la literatura de viajes, los informes administrativos y científicos, la novela, la poesía, los dibujos, las acuarelas y la pintura. A lo largo del siglo XIX hasta mediados del siglo XX, la temática de "la bibliografía hispanoafricana" (Rodríguez Joulia, 1973) giraba en torno a tres ejes temáticos principales centrados en acontecimientos históricos estrechamente vinculados al proyecto colonial español: la conquista de Tetuán en 1860, el movimiento colonialista (1881-1892) y la campaña militar de Melilla en $1893 .{ }^{8}$ Esa incipiente producción literaria africanista española echa los cimientos de lo que se podría considerar como literatura colonial española sobre el Magreb.

En el Protectorado español de Marruecos, los primeros textos literarios escritos en lengua castellana por los habitantes nativos empiezan a publicarse hacia mediados del siglo XX. Esos agentes y productores culturales de la primera hora formaban parte de la élite nativa de la colonia: funcionarios, maestros, negociantes y miembros de los grupos hegemónicos tradicionales, es decir, la oligarquía local. Se convierten en los impulsores de esa incipiente tradición literaria magrebí en lenguas transcontinentales europeas como el francés o el castellano. Las expresiones culturales y estéticas en lengua castellana de autores como Sin Muhammad ben Azzuz Haquin, Gumara el Haila, Adberrahim Yebbur Oddi, and Sarif Sidi Abde-Al-Salma ibn Raysun, entre otros, se pueden enmarcar dentro de ese contexto. Las constantes temáticas que recorren esa producción literaria en lengua castellana, en el caso que nos ocupa aquí, destacan por su fuerte contenido etnográfico al recoger de forma continua y recurrente y desde diferentes perspectivas, la historia, las costumbres, los mitos, los rituales y la cultura de los diferentes grupos humanos que habitaban diferentes regiones del Magreb. Carlos Rodríguez Joulia (1973) observa a tal efecto que "los temas que cultiva(n) son precisamente los genuinos de su patria” (p. 11). Y no está de más resaltar que las prácticas discursivas de esos "literatos africanos de expresión española", siempre siguiendo a Rodríguez Joulia, se sitúan dentro del contexto de un proceso de recuperación y rearticulación cultural y

${ }^{8}$ La expresión y la periodización son de Carlos Rodríguez Joulia (1973). 
lingüística de una realidad cultural, social, política e institucional desarticulada e invisibilizada por el discurso colonial español. El proyecto colonial español, en el rebufo del europeo, privó a los habitantes del protectorado español de uno de los elementos esenciales de su identidad: el uso de la lengua propia en los espacios públicos de transacción y de interacción por medio de lo que el profesor y crítico centroafricano Victorien Lavou Zoungbo llama "la mémoire assignée" (2007). El acceso del llamado "sujeto colonial magrebi" a la cultura letrada colonial y el uso y manejo de la lengua importada e impuesta, el castellano en el caso que nos ocupa, les permitió desafiar e impugnar la hegemonía cultural y el monopolio lingüístico sobre el uso de esa lengua en los espacios político, cultural y social de interacción y de producción epistemológica en el caso del Sahara Español y en el Protectorado de Marruecos. Esos agentes y promotores culturales "periferizados" se propusieron de ese modo romper la estructura opresiva que el historiador tunecino Albert Memmi llama "la relation coloniale": "La relation coloniale enchaînait le colonisateur et le colonisé dans une espèce de dépendance implacable, façonnait leurs traits respectifs et dictait leurs conduites"; (p. 17).

Hacia mediados del siglo XIX, aparecen los primeros textos en lengua castellana escritos por los habitantes nativos de la colonial del Sáhara Español. La publicación de "El país que no conoce sultán ni dinero" (1854-1856), de El Cheij Ma El Ainin (1836-?), un relato de viajes donde el autor cuenta su peregrinación a la ciudad santa de Meca en Arabia Saudita, es parte de ese proceso escritural emergente. El Ainin hace un recuento muy detallado de la tradición del Hajj, uno de los cinco pilares del islam según el Corán. El Hajj es un viaje de paz y de reconciliación a los lugares santos del Islam: Meca y Medina. Asimismo, Ramon Mayrata (2005), el prologuista del libro, refiriéndose al autor, observa "En el parecen encarnarse la resolución y la utopía de una cultura empeñada en prevalecer en unas circunstancias históricas que se han modificado" (2005: 15). Por medio de la reformulación y reconfiguración de historias personales y, por ende, historias colectivas, creadores culturales como Cheij Ma El Ainin consiguen desafiar y cuestionar "la mémoire assignée" colonial, es decir, la percepción y representación del sujeto colonial africano del norte de África, construida e impuesta por el discurso hegemónico español y europeo. En este sentido, el estudioso ghanés Komla Mossan Nabukpo (1990) observa que, 
al interpelar al conquistador en la lengua que domina y habla con soltura, es decir, su propia lengua, los africanos estaban poniendo un límite a su poder; es darle al colonizador un tratamiento médico apropiado para curarle de la saludable "amnesia estratégica gracias a la cual, hasta la fecha, sólo había querido, acordarse de el mismo; para el colonizado, significa negarse a quedarse quieto en el espacio que le había asignado el colonizador; es asimismo un acto de crítica (p. 404; Traducción propia)

Al narrar de forma detallada las peripecias de su viaje hacia Meca como parte de un acto de fe tan importante para los musulmanes como es la peregrinación del "Hajj", Cheij Ma El Ainin aprovecha su paso por diferentes espacios geográficos y sus encuentros e intercambios con gente de otras culturas para compartir otras expresiones culturales, religiosas y sociales y, de paso, ofrecer visiones alternativas sobre el Islam, la cultura árabe y África del Norte. En este sentido, se puede afirmar que "El país que no conoce sultán ni dinero" forma parte de una propuesta discursiva revisionista con vistas a articular una alternativa epistemológica y ontológica al discurso colonial español sobre África del Norte y el Magreb en general. El Ainin propone lo que el crítico y profesor senegalés Mohamadou Kane (1985) llama "une vision du dedans".

La literatura magrebí de expresión en castellano empieza a manifestarse de forma continua, aunque no profusa, a partir de los años 50 del siglo XX coincidiendo con el surgimiento del movimiento nacionalista político y cultural que nace después de la Segunda Guerra Mundial que reclamaba la liberación de los territorios colonizados por diferentes países europeos de la época. El proyecto nacionalista magrebí, salvando las distancias y las diferencias, pugnaba por abrir y crear un espacio de expresión a partir del cual cuestionar el monopolio colonialista y, de paso, "threatening the exclusive claims of the center", en palabras de Bill Ashcroft (1989). El movimiento nacionalista, cultural y político, proponía otros modos de representación y la creación de "espacios de subjetividad" alternativos con vistas a reclamar y articular una identidad cultural propia $\mathrm{y}$, de paso, abrogar la memoria asignada y, por ende, la alienación cultural. En el campo literario, esa práctica discursiva no solo rescata la agencia del sujeto colonial y colonizado norteafricano, sino que deconstruye la estructura de invisibilización y de desresponzabilización histórica y cultural construida por la ideología colonial española y europea en 
general. ${ }^{9}$ De ese modo, procede a la validación y legitimación de su Historia y cultura. Seamus Deane (1990) observa:

In the attempted discovery of its "true" identity, a community often begins with the demolition of the false stereotypes within which it has been entrapped. This is an intricate process, since the stereotypes are successful precisely because they have been interiorized. They are not merely impositions from the colonizer on the colonized (p. 12).

Es un proyecto discursivo e ideológico que busca abrir un nuevo espacio epistemológico y proponer saberes alternativos y legítimos sobre África del Norte, el Magreb, la cultura árabe y el islam. El protectorado de Marruecos y la colonia francesa de Túnez consiguen la independencia de Francia en 1956. En ambos países, tanto durante la época colonial como en la posindenpendencia, el árabe normativo y el francés cohabitan dentro del mismo espacio geopolítico como lenguas co-oficiales y nacionales. Son vehículos lingüísticos que sirven también de medios de expresión institucional, cultural y estético y de plataformas de transacción e interacción nacional y transnacional. Junto con Argelia, Marruecos y Túnez usan una lengua común, el Árabe normativo, aunque con ligeras variantes dialectales, que sirve de vehículo lingüístico nacional, regional, transregional y transnacional. También comparten la misma religión, el Islam, la misma historia, la arabidad y la habitan etnias emparentadas en algunos casos. Si bien la lengua castellana sobrevivió en algunos círculos sociales y "reductos" o "enclaves" culturales, así como en espacios académicos como las universidades en Marruecos, Túnez y Argelia, su presencia en los espacios públicos e institucionales de transacción es limitada por no decir casi inexistente. El castellano no llegó a alcanzar la categoría de lengua oficial o de lengua nacional en Marruecos, a excepción del norte del reino y sobretodo en la zona fronteriza con las ciudades españolas de Ceuta y Melilla, donde el castellano llega a ser usado, en algunos casos, como lengua de comunicación cotidiana y de interacción. Túnez, en cambio, no ha tenido el mismo nivel de intercambios ni la intensidad de interacción continua con el castellano y la cultura hispana que Marruecos. Según Manuel Gahete et al. (2008), el uso de la lengua castellana y su diseminación estaba más bien restringido a los círculos académicos:

${ }^{9} \mathrm{El}$ concepto de "desresponzabilización histórica" es del sociólogo español Imanol Zubero. 
En cuanto a Túnez, hay que indicar que el hispanismo se encuentra, en estos momentos, y después de un gran trabajo desarrollado desde las universidades de la Manouba y del Instituto Superior de Lenguas de Túnez, en un proceso de madurez y fortalecimiento excelentes (pp. 39-40).

El 16 de octubre de 1975, el Reino de Marruecos organizó la llamada Marcha Verde con el objetivo de reconquistar "las provincias sureñas de Marruecos" según afirmó el Rey Hassan II en aquel entonces. Unos 350.000 ciudadanos marroquíes protegidos por las Fuerzas Armadas Reales (FAR) "invadieron pacíficamente" la colonia del Sáhara Español ante la pasividad de los militares y los guardas fronterizos españoles. ${ }^{10} \mathrm{El}$ 14 de noviembre de 1975, se firmó el Acuerdo Tripartita de Madrid que "repartió" el territorio del Sáhara Español entre el reino de Marruecos y la República Islámica de Mauritania. ${ }^{11}$ La ocupación de Smara el 27 de noviembre y de El Aiún el 11 de diciembre de 1975 por las fuerzas armadas de Marruecos provoca el éxodo masivo de la gran mayoría de la población del Sáhara Español y su alejamiento de los espacios locales y tradicionales de lo que iba a ser el territorio nacional de la República Árabe Saharaui Democrática (RASD). Nace la diáspora saharaui. ${ }^{12}$ El 28 de febrero de 1976, el Frente Polisario proclamó oficialmente la fundación de la RASD en el pueblo de Guelta Zemur, en los territorios liberados, desencadenando la lucha de liberación nacional contra los ejércitos de Marruecos y de Mauritania. Como movimiento nacionalista, el Frente Polisario, encabezó la lucha de resistencia contra el colonialismo español y más tarde la lucha armada contra Marruecos y Mauritania para la liberación e independencia del Río de Oro. La militarización del problema saharaui con el consiguiente conflicto armado "(...) conllevó a los saharauis a reproducir

\footnotetext{
${ }^{10}$ La Marcha Verde fue condenada por el Consejo de Seguridad de las Naciones Unidas en su resolución núm. 380 del 6 de noviembre de 1975.

${ }^{11}$ Entre 1970 y 1973, mientras los militantes del OALS cumplían sus condenas en las cárceles de Canarias y Guelta, el movimiento se fue rearticulando; esta vez alrededor de un movimiento revolucionario encabezado por un grupo de jóvenes exiliados también en el sur de Marruecos tras la operación Teide. Formados en la ideología anticolonial de la época, floreciente en las universidades magrebíes donde se formaron, fundaron el 10 de mayo de 1973 el Frente por la Liberación de Saquia El Hamra y Río de Oro (Frente Polisario). El poeta Ahmed Mahmud relata ese momento histórico; véase Les Cahiers d'EMAM (2015), pp. 24-25 (consultado el 09 de febrero de 2019).

${ }^{12}$ Se estima que más de 350.000 saharauis viven refugiados en los campamentos de Tinduf en Argelia
} 
su organización en los campos de refugiados establecidos cerca de Tinduf, Argelia, en el lugar conocido como Hassi Robinet, en medio del desierto". ${ }^{13}$ Tras 20 años de conflicto, el 6 de setiembre de 1991, se firmó un alto el fuego entre el Frente Polisario y Marruecos bajo los auspicios de la Organización de las Naciones Unidas. Más de treinta años desde la firma del acuerdo de Madrid que debía culminar en un referéndum, el Sáhara Occidental aún sigue bajo ocupación marroquí. La RASD es una realidad política, social y cultural única y problemática en tanto y en cuanto que como sujeto de derecho internacional, su legitimidad como estado-nación soberano descansa en la fragmentación del territorio nacional y la transterritorialidad.

En este estudio nos apoyaremos en la propuesta teórica y crítica de Giles Deleuze y Felix Guattari sobre la noción de desterritorialización desarrollada en su estudio sobre la obra de Frantz Kafka, Pour littérature mineure (1997) y en Mille plateaux (2000). La noción de desterritorialización con sus connotaciones históricas, sociológicas, antropológicas, psicológicas, económicas y políticas está vinculada al discurso de la espacialidad y a la construcción de la localización por medio de la re-territorialización o reconfiguración espacial. En este sentido, Henri Lefebvre (1976) observa que,

El espacio no es un objeto científico ajeno a la ideología o la política; ha sido siempre político y estratégico. Si tiene un aire neutral y de indiferencia por sus contenidos, lo que lo hace parecer tan solo "formal", epitome de abstracción racional, es precisamente porque se lo ha ocupado y usado (p. 31).

La espacialidad, el desplazamiento y sus diversas representaciones ocupan un lugar prominente en la categoría de desterritorialización. Según Deleuze y Guattari tres características la conforman: la desterritorialización de la lengua y del lenguaje; el carácter político de esa producción cultural y su configuración como expresión de un discurso colectivo. La desterritorialización implica, por un lado, una separación voluntaria o forzosa y hasta violenta en algunos casos, del lugar de origen. También conlleva el alejamiento de los espacios personales y locales del lugar de origen, y conlleva diferentes niveles de alienación, de desarraigo $\mathrm{y}$ de reterritorializaciones en espacialidades transnacionales. Para complementar el citado aparato crítico y teórico, recurriremos en parte a la

${ }^{13}$ Véase Zidane Zerouai (2003) "Sahara Occidental: el conflicto olvidado", Revista de Estudios, Universidad de Costa Rica, 17, p. 220. 
categoría de "transterritorialidad". Si bien la experiencia transterritorial ha sido sinónimo de in/emigraciones internacionales y de cosmopolitismo, nuestro uso se limita a la movilidad transnacional como exilio y en sus múltiples facetas emocionales, simbólicas e identitarias.

La espacialidad define la historia de la RASD, un sujeto de derecho internacional y nacional parcial, es decir una nación sin estado, el gobierno de la RASD no tiene una soberanía efectiva sobre todo el territorio nacional. Gran parte de las instituciones de la RASD operan en y desde la transterritorialidad y la mayoría de los asuntos oficiales e institucionales se ha llevado a cabo en espacios transnacionales y transterritoriales; desde los territorios liberados, pasando por Argelia, y el resto de África, las Islas Canarias, España y las Américas donde se formaron de ese modo, comunidades políticas y socioculturales transnacionales saharauis en diferentes localizaciones geográficas pero manteniendo vínculos con un territorio nacional elusivo en la medida de lo posible. Ese proceso complejo y precario se enmarca dentro del proceso de construcción de una conciencia e identidad transnacional saharaui. ${ }^{14}$ Dada la fragmentación física del territorio nacional de la RASD dividido por el inmenso muro de "protección" construido por Marruecos para "proteger" las infraestructuras del país "útil y productivo" de los ataques del Frente Polisario, el espacio y la ubicación/localización desempeñan un papel central en la definición y articulación de la identidad nacional Saharaui. En efecto, la historia saharaui desde el acceso a la soberanía esta mediada por lo que la activista maliense Aminata Dramane Traoré (2011) llama Migrance, caracterizado por la dislocación y el desplazamiento forzado y precario a través de diversas geografías sin otro rumbo especifico; significa alejamiento de los espacios locales y orgánicos y la búsqueda de un espacio estable donde ubicar la comunidad saharaui. El novelista y ensayista senegalés Boubacar Boris Diop (2014) describe la Migrance como "movimiento e incertidumbre". Emprender la migrance no es de libre elección al ser, en la mayoría de los casos, una situación o circunstancia impuesta al individuo como en el caso de los saharauis cuyo país fue invadido y ocupado. La movilidad por la geografía de la transterritorialidad conlleva riesgos ya que suele implicar enfrentamientos a situaciones y a

\footnotetext{
14 “Una mirada sobre la situación de los 165.000 refugiados en Tindouf (Argelia). Allí, en un desierto donde solo crece el desaliento y el deseo de guerra, sueñan con su tierra y sobreviven desde hace 35 años de la ayuda externa. Véase L. Huete Machado (2010) "Sáhara, desierto y (des) esperanza," El País, 3 de octubre, p.1.
} 
experiencias de precariedad social, cultural y psicológica, así como de vulnerabilidad jurídica y económica. En muchos casos, el sujeto en desplazamiento carece de marcadores identitarios y está sumido en un proceso constante de desterritorialización física, social y psicológica, y también de reterritorialización, de negociaciones y renegociaciones identitarias. Así lo expresa el poeta saharaui Bahia Mahmud Awah en "Un poema eres tú",

Una mujer entre rejas

gritó:

¿Qué es un poema?

$\mathrm{Y}$ un poeta desde su exilio

le respondió:

Eres tú.

Nosotros, la fuerza,

la razón

de un verso y un poema ${ }^{15}$

Y Abderrahman El Fathi, en "Mariposas en Ramallah" (2003):

Y ahora en Tierra

Refugiado, en el exilio

También refugiado

En la calle exiliado

De nuevo refugiado,

Desplazado en tierra.

Humillado, triste y siempre

Refugiado en tierra sagrada (p. 42)

En los últimos 44 años, la historia de los ciudadanos de la RASD ha sido marcada por la experiencia de la migrance, definida por la localización en geografías agrestes y adversas como la Hamada en los campamentos de refugiados de Tinduf en Argelia donde se encuentra la mayor comunidad saharaui. Tinduf, ubicado en el desierto argelino,

\footnotetext{
${ }^{15}$ Pablo San Martín y Ben Bollig (2010) "Poesía Saharaui. Lucha y Resistencia en el Sáhara occidental”, en Confines. Arte y cultura desde La Patagonia

(http://www.confinesdigital.com/conf15/poesia-saharaui.html; consultado el 4 de febrero de 2019).
} 
representa lo que Marc Augé (2000) llama "no-lugar", es decir, espacio indefinido sin referentes espaciales e identitarios otros que el trauma y diversos niveles de desterritorialización. Es un lugar que Dominique Rolland define como "l'entre-deux", un espacio donde la legitimidad y la identidad del sujeto saharaui en desplazamiento no solo es cuestionada por la geografía sino que a menudo es negada, haciéndola inalcanzable, ${ }^{16}$ como escribe el poeta Saharaui Limam Boicha:

Después de tantos años y vivencias en una cultura tan distinta a la nuestra hizo que al volver tuviéramos que reeducarnos, re-aprender los códigos culturales, las costumbres, la propia lengua que se había quedado estancada en los años de la niñez. Pero sobre todo tuvimos que aceptar que todo seguía igual. Es cierto que había más medios que cuando nos fuimos pero en general todo seguía igual, nuestras familias seguían estancadas en el círculo vicioso del exilio, de la rutina diaria en los campamentos. ${ }^{17}$

En la geografía de "l'entre-deux", tanto la creación como la producción cultural suelen darse desde espacios marginales, de ahí su situación cultural periférica y de-centrada con respecto a la literatura y a la historiografía "nacional", ya sea en Marruecos, Túnez, Argel e incluso en España. A tal efecto Rodolfo Gil Benumeya Grimau (2008), resalta que "se produce una literatura en español paralela a la propia en cada lengua de cada país" (p.13). Partiendo de esas premisas, Álvaro Fernández Bruno y Florencia Garramuño (2003), preguntan,

¿Cómo interrogar al sujeto nómada e inestable que evocan la (in)migración, el exilio y la diáspora? ¿Cómo leer la proliferación de sentido-la movilidad y la incertidumbre de su lugar- sin volver a fijar su propio abandono de las raíces, su oposición al Estado, su emigración de la ciudadanía, su cosmopolitismo? La errancia entre dos (o más) culturas y la proyección de ficciones de identidad generada por los desplazamientos individuales y colectivos nos permite pensar al sujeto migrante en un lugar doble, híbrido y no unitario (p. 11).

En este sentido, es preciso resaltar que gran parte de la literatura norteafricana de expresión en castellano se caracteriza, tanto en su producción como en su consumo por lo transterritorial. Se vale, en muchos casos, de lo que definiremos como "la palabra migrante" o "palabra en desplazamiento", según el caso, y que no tiene un punto de anclaje

${ }^{16}$ Le Français dans le Monde, 352.

${ }^{17}$ Carmen Gómez Martín (2011) “Entrevista a Limam Boicha”, en RIPS, 12, 2, pp. 234 235. 
territorial fijo.. En la producción cultural de los autores y autoras saharauis como Salka Embarek o Limam Boicha o la cantante Aziza Brahim, que nació y se crió en la geografía de la migrance, el desplazamiento es físico y psicológico. Esa palabra en desplazamiento puede ser también metafóricamente migrante o de-centrada como en el caso del poeta tunecino Ridha Mami o el poeta marroquí Abderahman El Fathi que viven en países donde el castellano es una lengua periférica en los espacios públicos de interacción y de transacción, es decir,

(...) intellectuals from the Maghreb have lived on a frontier that cuts through language, religion, and culture. In their Works Maghrebian Francophone writers frequently describe what it is to be an exile, even in one's own country, separated from the rest of the population through education and the use of a language that belongs to the Other. ${ }^{18}$

Pese a estar presente en los círculos académicos, la literatura magrebí de expresión en español se erige como un discurso en tránsito en busca de un lugar de enunciación propio. Sin embargo, esa búsqueda no siempre significa un desplazamiento que implique una separación y un alejamiento físico del lugar orgánico como en el caso de los saharauis, puede darse dentro de los límites del territorio nacional y manifestarse por medio de lo que Rosi Braidotti (1994) describe como "la subversión de las convenciones establecidas, no el acto literal de viajar" (p. 33). Así se expresa en el "Dispensa de edad" (2008), de Said Jedidi (Marruecos)

Tetuán fue y sigue siendo otra cosa..., algo que no necesita figurar en los folletos turísticos. Su código, su lenguaje y su visión de futuro no correspondían en absoluto a los criterios de los que, por obra y gracia de una de estos paréntesis de la historia del país, se convirtieron en "hombres fuertes". Pero, como todos los 'hombres fuertes' acabaron por creer que eran inoxidables. Tanto que, padeciendo el incurable síndrome de "ruralitis". Tuvieron la audacia de imponer una elite, en un entorno donde siempre y para siempre fue expresión cultural y geográfica (p. 153):

en “Tentación”(2008), de Mezzouar El Idrissi (Marruecos):

${ }^{18}$ Farida Abu Haidar (1999) "Wandering Between two Worlds: Maghrebian Literature and the Redefinition of Boundaries," en E. Anthony Hurley et al. (eds.), Migrating Words and Worlds. Pan-Africanism Updated, Trenton, NJ/Asmara, Eritrea, Africa World Press, p. 99. 
¡Oh país mío dividido entre mí y mí como mi paso y mi sombra!

que me arrastres

hermoso

para que yo suba encima de mí mismo.

Te lleve cual canción en mis entrañas, para que vague el viento de las estrellas fugaces

arrastrando las tristezas de las tierras, lejos de las oscuridades de los senderos

País mío,

Devuélveme a mí mismo para que yo pueda ver

el roble de mi tiempo

poniendo a la sombra mi mapa

con el humo del comienzo (p. 231) ${ }^{19}$;

en "Mariposas en Ramallah (2003), de Abderrahman El Fathi (Marruecos),

Las palabras se rebelan

Los ríos se secan

Y los mares llorón tristezas,

Desembocan en todo volcán del miedo.

Las montañas en palabras,

Todo llanuras, todo seco,

Se rasga el dolor, se silencia

La justicia y se rebelan también los ángeles

Del firmamento

Y solo se oían voces de palabras lejanas (p. 34).

Y en "La dignidad y el honor de mi pueblo" (2011), del tunecino Ridha Mami,

En el invierno,

Un invierno que no nos ha tocado

Vivir desde que pasaron cincuenta

inviernos, dicen,

el catorce de enero,

al grito de ¡Libertad, dignidad, trabajo!,

${ }^{19}$ Poema recogido en la antología Calle del Agua (2008). 
Barrimos veintitrés años de despotismo (p. 85).

Para los autores y las autoras saharauis del grupo literario La Generación de la Amistad, inmersos en la cultura del exilio y, por ende, del desarraigo y de la desterritorialización, el lugar de enunciación del discurso lírico ocurre en y desde la transterritorialidad. Se expresa a través de diversas vivencias personales y colectivas como la espera en "Esperando en el camino", de Bahia Mamud Awah:

Más de treinta años saludando

el paso indiferente

de muchas caravanas

que no se fijaban

en mi rostro ya dilatado por los

años de espera.

Nadie dijo,

pobre confinado en la inmensidad

de su espera.

Tampoco supieron decirme

muerto

en el camino.

Al paso de sus caravanas les agito

mis firmes brazos

convencido

y seguro como una estatua de la libertad

que los tiempos no han podido derribar ${ }^{20}$

La activación de la memoria en "No olvido", de Mohamed Ali Ali Salem

No olvido, compañera, la inminente presencia

de días atrapados,

de amaneceres mutilados

en la lóbrega garganta

de las noches de exilio.

\footnotetext{
${ }^{20}$ Poema recogido en "Poesía Saharaui. Lucha y Resistencia en el Sahara occidental", en Confines. Arte y cultura desde La Patagonia

(http://www.confinesdigital.com/conf15/poesia-saharaui.html; consultado el 4 de febrero de 2019).
} 
Ni mis años, temprano vividos

y roturados en mis calles natales

añoradas hasta la demencia.

Mi tierra,

lugar de donde vengo,

a donde voy.

Encadenada nación,

razón de mi diáspora,

de mi lucha,

de mis pasos y mis alas

que no cesan:

porque se saben esperadas ${ }^{21}$

La temporalidad en "El tiempo va", de Luali Lesham:

El tiempo va, siempre va

dejando callos en las manos

de la historia.

Los años se precipitan

como perlas de un rosario

sobre la ya longeva memoria

del exilio ${ }^{22}$

o el trauma de la guerra en "Sobrevivir a la guerra", de Mohamed Salem Abdelfatah (Ebnu)":

Quién dijo

que se terminó la guerra.

Quizá para los muertos.

Sobrevivir a la guerra

es llevar acuestas el cuerpo ausente.

Y el corazón emboscado en una batalla

lleno de gritos que nos congelan el alma ${ }^{23}$

\footnotetext{
${ }^{21}$ Ibidem (consultado el 4 de febrero de 2019).

${ }^{22}$ Ibid. (consultado el 4 de febrero de 2019).

${ }^{23}$ Ibid. (consultado el 4 de febrero de 2019).
} 
El discurso de la espacialidad y del desplazamiento es un tema recurrente en la práctica cultural y nacionalista del grupo literario de "La Generación de la Amistad cuyo objetivo es "transmitir en verso y prosa la esencia del pueblo saharaui". ${ }^{24}$ La tematización de la experiencia transnacional física y simbólica a través de una diversidad de voces y de proyectos culturales define, en gran medida, la literatura Saharaui de expresión en castellano desde la época colonial hasta la actualidad. Casi todos los integrantes de este grupo literario nacieron en la entonces colonia del Sáhara Español; se trata, como observa Carmen Gómez Martín (2013), de “(...) un grupo literario heredero de los poetas revolucionarios que durante las décadas de 1970 y 1980 combatieron en las líneas del Frente Polisario contra la ocupación marroquí del Sáhara Occidental". La experiencia de la migrance forma parte, una forma $\mathrm{u}$ otra, de sus vivencias definidas por la dislocación emocional, psicológica y cultural. Los campamentos de refugiados de Tinduf fueron convertidos de ese modo en comunidades transnacionales saharauis y en un territorio estado-nación ad hoc como resalta el poeta Limam Boicha, "ahora van y vienen a una tierra prestada, ese lugar en cuyo cielo "Dios solo sembró estrellas y deseos...", y "desde donde añoran la propia": "Recuerda que existe una tierra sin amo y sin dueño" según Ali Salem Iselmu. Lola Huete Machado los llama Poetas andantes “(...) con el sol en la piel, bien activos, que se han agrupado para contar su cultura y su drama" (...), y que, "Hablan y narran en español hermosos poemas que describen el drama de su pueblo, del color de la jaima y del desierto" (El País Semanal, 27 de marzo 2013). ${ }^{25}$ En el poema La quinta estación, Limam Boicha escribe,

\footnotetext{
${ }^{24}$ Ebbaba Hameida Hafed (2014) "Zahra, la flor en la poesía. Entrevista con la poeta saharaui Zahra Hasnaui”, en La voz Ascendente. Género y creación tras las revoluciones árabes, Espéculo. Revista de Estudios Literarios, Madrid, Universidad Complutense, 53, p. 77.

${ }^{25}$ Poetas andantes, con el sol en la piel, bien activos, que se han agrupado para contar su cultura y su drama. Son Limam Boisha (Atar, 1972; reside ahora en Madrid), Alí Salem Iselmu (1970, Villa Cisneros; ahora en Vitoria), Bahia Mahmud Awah (1960, Auserd; en Madrid), Zahra Hasnaui (1964, El Aaiún; en Guadalajara), Sukeina Aali-Taleb Fernández (1975, nacida en Madrid). Otros miembros son también Luali Lahsan (reside en Alicante), Chejdan Mahmud Yazid (ahora en los campamentos), Saleh Abdalahi (en Mallorca), Mohamed Salem Abdelfatah, Ebnu (que reside en Uruguay); véase El País Semanal, 27 de marzo de 2013, p. 3.
} 


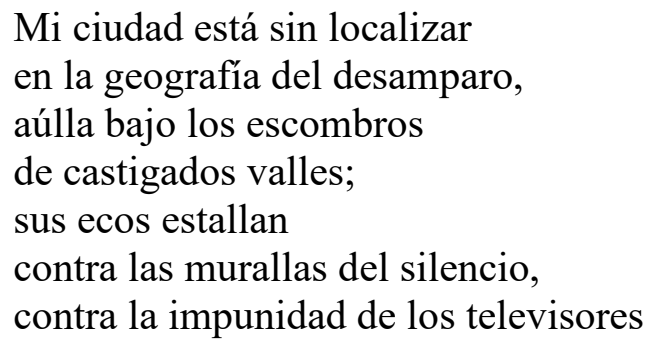

En este mismo sentido se expresaba la cantante de Jazz saharaui Aziza Brahim cuando afirmó que "Yo no conozco a mi país". Brahim nació en un espacio transnacional, en un campamento de refugiados que carecía de referentes culturales e identitarios orgánicos otros que la experiencia del trauma, de la desterritorialización y del desarraigo. Reterritorializada en otra geografía lingüística, cultural y social transterritorial y ajena, Aziza Brahim junto con los/las saharauis de la diáspora se vio sumida en un proceso de búsqueda de localidad estable donde construir un hábitat estable en la transnacionalidad. El proyecto discursivo de La Generación de la Amistad recoge y refleja esa tensión y alteridad anclada en la violencia de la historia como se expresa en el poema También en el desierto crecen flores, de Limam Boicha:

"Mi tierra, lugar de donde vengo, adonde voy".

Unos y otras hablan de la hamada y la badia, dos desiertos bien distintos; de melfas, camellos, jaimas, canciones, batallas; de lugares como Tiris, Tifariti o Tindouf, de la baraka y los espejismos, de los versos escritos en la madera que luego se beben para fecundar la mente, de los beduinos... "Los hubo y los hay"

Ello implica una reterritorialización física y simbólica encaminada a recuperar la memoria saharaui mediada por el dolor y la alteridad e inscribirla en la narrativa de la Historia Nacional. El espacio transnacional, dentro de ese contexto, se convierte y perfila como un lugar propio, orgánico y un hábitat donde se aspira a establecer nuevas comunidades transnacionales y dinámicas dando pie a nuevos encuentros y a la construcción de espacios de interacción, de diálogo y de intercambios de 
experiencias donde la identidad está sujeta a múltiples negociaciones y constantes reinterpretaciones, y mediadas por diversas modalidades de interacción e intercambios así como nuevas responsabilidades sociales e identitarias. Isabel Montés García (2007) observa a tal efecto que, "new subjectivities are being constructed in the process of reclaiming localities in order to establish a new sense of community" (p. 2). La nacionalidad, para los saharauis, es elusiva en tanto y cuanto que carece de los parámetros que la definen: un gobierno nacional con sus instituciones dentro de un territorio nacional con fronteras reconocidas internacionalmente y una comunidad nacional y una identidad nacional y cultural colectiva. La nacionalidad, en este sentido, como recalca James Mc Dougall (2003) se define como una "(...) nation in unifying forces of identity, that is, in a shared sameness of historical experience, cultural world and political belonging" (Introduction, 1). En este sentido, para los autores y las autoras de La Generación de la Amistad, el desplazamiento orienta y legitima la construcción de una identidad colectiva transnacional como parte del discurso de resistencia y de denuncia de la usurpación y "secuestro" del territorio nacional saharaui. A tal efecto, la propuesta y práctica discursivas de la Generación de la Amistad gira en torno a la experiencia de la migrance y a la búsqueda empecinada e incierta de lugar, de ubicación y de un hábitat nacional. Asimismo propusieron nuevas prácticas culturales reconfigurando las formas de producción con vistas a construir un discurso nacionalista homogeneizado por una historia común de dolor, de trauma y de desterritorialización.

Por sus circunstancias particulares, la literatura magrebí de expresión en castellano surge, evoluciona y se consume, si cabe, en un espacio que el crítico Jacques Chévrier (2004) llama un "nouvel espace identitaire", una espacialidad dinámica e híbrida marcada por la desterritorialización de las prácticas culturales y estéticas donde ocurren diversos procesos de diálogos, de negociaciones y de legitimación. En una geografía tan elusiva y precaria como ésa, la práctica escritural suele posicionarse y evolucionar en y/o desde la periferia de la historiografía literaria nacional y está caracterizada por una visibilidad opaca y un consumo marginal pese a sus aspiraciones a estar presente en los espacios públicos y canónicos de países como Marruecos, Túnez y Argelia, en el caso de los saharauis. Abderahman El Fathi (Marruecos), por citar un ejemplo, se considera como "un escritor de la frontera" (2013), su lugar de elocución es un espacio de tránsito: la ciudad "fronteriza" de Ceuta, un lugar de paso, un puente entre dos mundos y dos continentes, y también un espacio de 
esperanza como se manifiesta en La Mar, un poema donde la voz lírica reflexiona de forma angustiosa sobre la trágica e incierta experiencia de la migrance:

Desaparece el dolor

Las olas se lo han llevado

Aparecen los tiburones se llevaron el anillo.

Espera una marea

La Guardia Civil

Se lo ha traído.

Las novias lloran

En un puerto sin barcos, sin gaviotas

Con pateras

Con MUERTE.

Y una madre espera a su hijo

Pero una ola se enamoró del moreno

Y a las profundidades lo arrastró (pp. 21-22)

En la novela El diablo de Yudis, de Ahmed Daoudi (1994), la incertidumbre de la migrance que acompaña la movilidad geográfica se transforma aquí en una esperanza elusiva:

En aquel momento me sentía que la verdadera aventura estaba por empezar. Todos mis sentidos se refugiaban en el sueño de conseguir mucho dinero para no palpar el riesgo que iba a correr. Imaginaba que después de llegar a la otra orilla habría un coche esperándonos y en el iríamos directamente a Francia, donde yo trabajaría unos cuantos meses como temporero en el campo. Cuando tuviera dinero suficiente continuaría el viaje a Inglaterra. Allí intentaría colocarme en un puesto fijo. En cuanto ahorrase cinco mensualidades enteras volvería para comprar una casa o una parcela; volvería en un coche grande; volvería como si hubiera nacido de nuevo, pero con más suerte (p. 94).

Para Mohamed Chakor (Marruecos), en cambio, evolucionar en los espacios transnacionales implica la articulación de la memoria como forma de resistencia y de conservación del nacionalismo. Se trata de una memoria mediada y definida por la alteridad al referirse a un lugar distante que se erige como referente y hogar de su identidad cuestionada en la transterritorialidad. En el poema Poema 11,

Dime como fue 
aquello que se fue.

Háblame del frío

matinal del invierno,

cuando aun dormidos

íbamos a estudiar.

Háblame de los compañeros

que no hemos vuelto a ver,

y que se fueron

en la vida como

ella en los días (...)

Háblame de aquello

que veíamos brillar

en el fondo del mar,

que creíamos ser

tesoro legendario,

y que era el solo.

Díme como fue

aquello que era verdad (pp. 238-39);

Mezouar el Idrissi recoge la transterritorialidad simbólica en Tentación,

O país mío dividido entre mí y mí

Como mi paso y mi sombra

Que me arrastres;

Hermoso

Para que yo suba encima de mi mismo.

Te lleve cual canción en mis entrañas,

Para que vague el viento de las estrellas fugaces

Arrastrando las tristezas de las tierras,

Lejos de las oscuridades de los senderos.

País mío,

Devuélveme a mi mismo para que yo pueda ver

el roble de mi tiempo

poniendo a la sombra mi mapa

con el humo del comienzo (pp. 230-231)

Y por último en Cantos a mi tierra, de Moisés Garzón Sefarty, 
Esperé volver a ti desde el fondo de los siglos

Desde un remoto tiempo sin edades.

Te busqué entre las ruinas del mundo,

añoré tus piedras y tus valles,

tus nieves y tus primaveras,

tus mares y tus arenas (p. 193)

La recuperación y articulación de la memoria histórica y cultural forman parte del proceso de construcción de nuevos modos de producción cultural enfocados a compartir experiencias comunes y a mantener vínculos sociales, culturales, afectivos e identitarios con el lugar de origen. Para el sujeto magrebí en desplazamiento físico o simbólico, la activación de la memoria forma parte de una estrategia encaminada a mitigar el desarraigo, la tensión y el dolor de la desterritorialización física o simbólica y, de paso, suplir la pérdida del hogar nacional o los espacios locales y la carencia de referentes espaciales, culturales y espirituales. Esa falta o hiato se manifiesta en la producción lírica de creadoras y creadores como Sara Alaoui y Mohamed Lahchiri (Marruecos), Ridha Mami y Mohamed Doggui (Túnez), entre otros, cuyo proyecto cultural se apoya en una escritura "de-centrada" ("décentrée") que se vale de una "tercera lengua" para su expresión estética, el castellano en el caso que nos ocupa. Tanto en Marruecos, Túnez como en Argelia, la práctica cultural de esos autores y autoras se restringe a los márgenes de la historiografía literaria nacional en la mayoría de los casos. ${ }^{26}$ En este sentido, se puede decir, siguiendo al crítico Réda Bensmaïa (2002), que la producción cultural de esos autores y autoras está marcada por el "nomadismo", una práctica cultural que fluctúa entre distintas expresiones literarias coetáneas que, en algunos casos, llegan a intersectar. Este movimiento se da al menos entre tres prácticas literarias paralelas: dos en lenguas de préstamo, el francés y el español, marcadas por la hibridez. En el caso de como Ahmed Daoudi, Abdel Ahmed El Beyuki, Mohamed Lahchiri, con Pedacitos entrañables (1994), Cuentos ceutíes (2004) y Una tumba en Sidi Embarek (2006); Mo Toufali, con Gambri (1993) y Camilo (1993); Mohamed Chakor, "Diván sufí"; Abderraman El Fathi, con Triana: imágenes y palabras (1998), Fantasías literarias (1999), Abordaje (2000), Africa en versos mojados (2000), Desde la otra orilla (2000), Primavera en Ramallah y Baghdad (2003), entre otros. En su obra, este movimiento interactivo y fluctuante

${ }^{26}$ La expresión es de Jacques Chévrier (2004: 97). 
contempla cuatro espacios lingüísticos y literarios: la creación en árabe normativo o culto que recoge la experiencia de la nación árabe-islámica; la del árabe vernáculo y oral, como el dariya, el amazigh y el hassanya, marcada por el pragmatismo, la flexibilidad y la movilidad, y que contempla las grandes gestas y los mitos de la historia del pueblo y el imaginario árabe ${ }^{27} \mathrm{y}$, por último, la literatura que se expresa en las lenguas de préstamo como el castellano y el francés. Esos autores y autoras escriben y están inmersos en un proceso de interacción o de fricción cultural entre la hispanidad y la arabidad. Su lugar de enunciación se da en un espacio que el crítico francés, Jacques Chévrier, llama "un espace tiers" donde se embarcan en el esfuerzo monumental de definir y articular un espacio de creación, de producción y de consumo "hispánico" en un entorno social y culturalmente dominado por una literatura nacional de expresión en árabe y/o en francés. Por lo tanto, son creadores y creadoras culturales que ya no se pueden ni deben identificar meramente como individuos que escriben o que sólo "saben" escribir en castellano, en este caso, sino como individuos que realizan un vaivén cultural, escritural, lingüístico y estético, polivalente y fluido y a diferentes niveles entre expresiones y tradiciones literarias diferentes pero contemporáneas. ${ }^{28} \mathrm{En}$ este sentido, y siguiendo a Pierre Bourdieu, se puede afirmar que los autores norteafricanos de expresión en castellano han construido un "nouveau champ littéraire" cuyas normas quedan por articular y definir a partir de parámetros nuevos y alternativos dentro del marco de la historiografía literaria magrebí en general. ${ }^{29}$ Es un espacio polifónico que Abdelkébir Khatibi llama Maghreb Pluriel (1983),

\begin{abstract}
Nous, les Maghrébins, nous avons mis quatorze siècles pour apprendre la langue arabe(à peu près), plus d'un siècle pour apprendre le français(à peu près); et depuis des temps immémoriaux, nous n'avons pas su écrire le berbère. C'est dire que le bilinguisme et le plurilinguisme ne sont pas, dans ces régions, des faits récents. Le paysage linguistique maghrébin est encore plurilingue: diglossie(entre l'arabe et le dialectal), le berbère, le français, l'espagnol au nord et au sud du Maroc" (p. 173).
\end{abstract}

\footnotetext{
${ }^{27}$ Réda Bensmaïa (2002) “Territoires de la francophonie”, Le Français à l'université, 4, p. 5.

${ }^{28}$ Ibidem, p. 5. En este caso, estamos parafraseando a Bensmaïa que se refiere a los escritores francófonos como "celle ou celui qui écrit ou ne peut écrire qu'en français", p. 5.

${ }^{29}$ Hasanya es la lengua vernacular hablada en el Sáhara Occidental y en la diáspora; dariya, tachelhit, tarifit y tamazigt en Marruecos, y el darija o tunsi y tamazigh en Túnez.
} 
Plural y multidimensional, este proyecto cultural que favorece la emergencia y la construcción de espacios de interacción y de diálogos caracterizados por un proceso que describiremos como una "transhumance linguistique, culturelle et esthétique" al darse en un espacio dinámico, heterogéneo y multidimensional. Uno de sus rasgos definidores es lo que llamaremos la hispano-maghrebidad, una experiencia o, mejor dicho, experiencias mediadas por la movilidad, transregional y transnacional, tanto continental como transcontinental. Para los creadores, agentes promotores y otros trabajadores de la cultura magrebíes, las experiencias de la transterritorialidad tienden a promover la creación de modos y modelos discursivos alternativos con vistas a recuperar la iniciativa del lenguaje y del discurso. En este sentido, la literatura magrebí de expresión en castellano aspira a "decir" las múltiples vivencias de lo transterritorial como espacio alternativo con posibilidades de apertura, de diálogos y de construcción de nuevas realidades identitarias dentro del marco de la cultura arabo-islámica. 


\section{REFERENCIAS BIBLIOGRÁFICAS}

Abu Haidar, Farida (1999) "Wandering Between Two Worlds: Maghrebian Literature and the Redefinition of Boundaries", en E. Anthony Hurley et al. (eds.), Migrating Words and Worlds. PanAfricanism Updated, Trenton, NJ/Asmara, Eritrea, Africa World Press, 1999.

Augé, Marc (1992) Non-lieux. Introduction à une anthropologie de la surmodernité. Paris, Editions du Seuil.

Augé, Marc (2000) “Los no lugares", espacios del anonimato. Una antropología de la sobremodernidad, Buenos Aires, Geidisa editorial. Ashcroft, Bill et al. (1989) The Empire Writes Back. Theory and Practice in Post-Colonial Literatures, Londres/Nueva York, Routledge. doi.org/10.4324/9780203402627

Bensmaïa, Reda (2000) “Territoires de la francophonie”, en Le Français à l'université, (4ème trimestre) $\mathrm{n}^{\mathrm{o}} 4$.

Boicha, Liman (2004) Los versos de madera, Canarias, Editorial Puentepalo.

Castro, Mariano L. De y De la Calle, María Luisa (1992) Origen de la colonización española de Guinea Ecuatorial (1777-1860), Valladolid, Secretariado de Publicaciones de la Universidad de Valladolid.

Chakor, Mohamed (2005) Diván Sufi y otros poemas, Málaga, La Chilaba ediciones.

Chévrier, Jacques (2004) "Afrique(s)-sur-Seine: autour de la notion de "migritude", en Notre Librairie, Revue des Littératures du Sud, 155156 (juillet-décembre), pp. 96-100.

Correale, Francesco y Juan Carlos Gimeno Martín (2015) «Sahara Occidental: memorias coloniales, miradas postcoloniales », en Les Cahiers d'EMAM, 24-25 [http://journals.openedition.org/emam/760; consultado el 02 de febrero de 2019) doi: 10.4000/emam.760

Daoudi, Ahmed (1994) El diablo de Yudis, Madrid, Ediciones Vosa.

Ebbaba Hameida Hafed (2014) "Zahra, la flor en la poesía. Entrevista con la poeta saharaui Zahra Hasnaui”, en La voz Ascendente. Género y creación tras las revoluciones árabes, Espéculo. Revista de Estudios Literarios, Madrid, Universidad Complutense, número 53 (Juliodiciembre), pp. 77-81.

El Fathi, Abderrahman (2002) África en versos mojados, Tetuán, Universidad de Tetuán (Facultad de Letras), 2002. 
ElGheryb, Mohamed y Moreno Torregrosa, Pasquall (1994) Dormir al raso, Madrid, Ediciones Vosa.

El Idrissi,Mezouar (2008) “Tentación”, en Calle del Agua. Antología contemporánea de literatura hispanomaghrebi, Madrid, Sial ediciones (Casa de África), pp. 225-231.

Espeleta Olivera, Mariana (2012) "LatinoÁfrica se lee mejor desde Latinoamérica: revolución, identidad, género y poesía en el Sahara occidental,", en Chiara Bolognese, Fernanda Bustamante y Mauricio Zabalgoitia Herrera (eds.), Éste que ves, engaño colorido. Literaturas, culturas y sujetos alternos en América Latina, Madrid, Icaria, pp. 319333.

Fernández Bravo, Bruno y Florencia Garramuño (2003/eds.) "Introducción", en Sujetos en Tránsito. (In)migración, exilio y diáspora en la cultura latinoamericana, Madrid/Buenos Aires, Alianza Editorial.

Gahete, Manuel, Abdellatif Limami, Ahmed M. Mgara, José Sarria y Aziz Tazi (2008) Calle del Agua. Antología contemporánea de literatura hispanomaghrebí, Madrid, Sial ediciones (Casa de África).

García Figueras, Tomás (1945) La puesta en valor del continente africano (España ante el problema), Barcelona, Talleres Gráficos Rex.

García Figueras, Tomás (1966) "La acción africana de España entorno al 98", Madrid, CSIC/IEA.

Garzón Sefarty, Moisés (2008) "Cantos a mi tierra", en Calle del Agua. Antología contemporánea de literatura hispanomaghrebí, Madrid, Sial ediciones (Casa de África), pp. 187-193.

Generación de la Amistad (2007) Treinta y uno. Thirty one. A Bilingual Anthology of Saharawi Resistance Poetry in Spanish, Leeds, UK, ed. Sombrerete y Sandblast.

Generación de la Amistad (2007) Um Draiga: Poesía saharaui contemporánea, Zaragoza, Diputación de Zaragoza y Um Draiga.

Gómez Martín, Carmen (2013) "La literatura saharaui contemporánea y su desarrollo en el contexto migratorio español", en RIPS, 12, 2, pp. 229241.

Huete Machado, Lola (2013) "Poetas castellanos del Sahara", en El País Semanal, 27 de marzo (consultado 26-II-2016).

Huete Machado, Lola (2010) "Sahara, desierto y (des) esperanza," en El País, 3 de octubre.

Khatibi, Abdelkébir (1983) Maghreb pluriel, Paris, Denoël. 
Kane, Mohamadou (1985) "Le thème de l'identité culturelle et ses variations dans le roman africain francophone", en Ethiopiques, 3, 3, pp. 11-25.

Kane, Mohamadou (1982) Roman africain et tradition, Dakar, Nouvelles Editions Africaines.

Lavou Zoungbo, Victorien (2007) Outsidering. Liminalité des Noir-e-s. Amériques-Caraïbes, Perpignan, Presses Universitaires de Perpignan.

Mami, Ridha (2014) Lunas de otoño, Madrid, Sial/Pigmalión.

Mc Dougall, James (2003) "Introduction", en Journal of North African Studies, 8, 1 (Spring), pp. 1-13.

doi.org/10.1080/13629380308718492

Memmi, Albert (2002) Portrait du colonisé, précédé du portrait du colonisateur, Paris, Gallimard.

Montes-Garcés, Isabel (2007) Relocating Identities in Latin American Cultures, Calgary (Canada), University of Calgary Press.

doi.org/10.2307/j.ctv6gqqhz

Nabupko, Komla Mossan (1990) "La critique littéraire "africaine": Réalités et perspectives d'une idéologie de la différence", Canadian Journal of African Studies, 24, 3, pp. 399-417. doi.org/10.1080/00083968.1990.10803868

N'gom, M'bare (2013) Palabra Abierta: Conversaciones con escritores africanos de expresión en español, Madrid, Editorial Verbum.

Robles Picón, Juan Ignacio, Juan Carlos Gimeno Martín, Bahía Mahmud Awah y Mohamed Ali Laman (2015) «La poesía saharaui en el nacimiento de la conciencia nacional», en Les Cahiers d'EMAM, 24-25

[http://journals.openedition.org/emam/789; consultado el 09 de febrero de 2019] doi: 10.4000/emam.789.

Rodríguez Joulia de Saint-Cyr, Carlos (1973) "Literatura africana en lengua española", en Homenaje a Federico Navarro: miscelánea de estudios dedicados a su memoria, Madrid, Asociación Nacional de Bibliotecarios, Archiveros y Arqueólogos (ANABA), 405-418.

Rolland, Dominique (2007) "Traces effacées, mémoires oubliées", Le Français dans le Monde, 352, pp. 50-51.

San Martín, Pablo y Bollig, Ben (2010) "Poesía Saharaui. Lucha y Resistencia en el Sáhara occidental", en Confines. Arte y cultura desde La Patagonia [http://www.confinesdigital.com/conf15/poesiasaharaui.html; consultado el 4 de febrero de 2019]. 
Traoré, Aminata Dramane y Boubacar Boris Diop (2014) La gloire des imposteurs. Lettres sur le Mali et l'Afrique, París, Philippe Rey. 